\title{
Structural Behavior of Repaired Reinforced Concrete Beams with Glued Steel Plate and Carbon Fiber
}

\author{
Aamer Najim Abbas \\ Civil Engineering Department, Al-Mustansiriya University, Baghdad 14150, Iraq
}

\begin{abstract}
This paper investigates the strength and deformation characteristics of reinforced normal and high-strength concrete rectangular beams which failed in shear and repaired by external bonding of carbon fiber and steel plate. Five simply supported reinforced concrete beams with shear reinforcement are tested, three of which are made with NSC (normal-strength concrete) and the other two with HSC (high-strength concrete). The span of the simply supported beams is $0.9 \mathrm{~m}$ with $100 \mathrm{~mm}$ wide by $200 \mathrm{~mm}$ deep cross section. All five beams are tested under four-point bending. Careful repair process is adopted and proved successful. The aim is to restore or increase shear strength of these beams and to monitor their post-repair load-deflection behavior. The effect of concrete compressive strength on the behavior and strength of beams before and after repair is also investigated. Shear cracks patterns and their evolution are observed and discussed.
\end{abstract}

Key words: Repair, carbon fiber, steel plate.

\section{Introduction}

Concrete structures are usually subject to get failed in one or more structural members for various reasons. The exposure of the building to extra loads that were not taken into consideration in the design process or the exposure of the building to earthquake loads or an explosion will lead to concrete failure or crack in the structural members. This naturally leads to collapse of the building or a great damage in some of its parts. The need to devise ways for repairing damaged concrete and recover the original resistance of the affected concrete parts is crucial.

Rehabilitation of old or damaged structures is an alternative to replacing them. The repair of structural concrete elements after damage is not uncommon [1].

There are many ways to repair structural members. The application of any of these methods depends mainly on the degree of damage in concrete. Some damage can be repaired via epoxy injection when the cracks are less than 0.002 in. $(0.05 \mathrm{~mm})$ in depth. The

Corresponding author: Aamer Najim Abbas, M.Sc., lecturer, research field: structural engineering. E-mail: amir_najim@yahoo.com. technique generally consists of establishing entry and venting ports at close intervals along the cracks, sealing the crack on exposed surfaces and injecting the epoxy under pressure. Other types of repair can be used for serious damage in structural members, such as the loss of some parts of the concrete member by grouting with Portland cement or by inserting reinforcing bars and bonding them in place with epoxy. The method of stitching can be used also when there are wide cracks in structural members [2].

In recent years, some researchers concentrated on several modern techniques to deal with damaged concrete. These methods depend on addition of high tension strength such as steel sheets or carbon fiber sheets on the surface of structural member by using special epoxy materials to increase the moment of inertia of the member. External bonding of composite plates (steel and carbon fiber) to reinforced concrete structures represents an interesting alternative to steel bars and corrosion of the plate can be avoided.

Increasing the shear strength by using carbon fiber and steel plate has a certain beneficial effect. In 2006, Abdelhak and Omar [3] tested 22 reinforced concrete 
beams to make a comparison between strengthened beam with carbon fiber and others without carbon fiber. They found that the carbon fiber beam has good shear strength of strengthened beams in comparison with other specimens without carbon fiber.

In 2006, Carlo and Claudio [4] made an experimental and theoretical study to certify the beneficial effect of carbon fiber on improving shear strength of concrete beams. They tested 12 reinforced concrete beams using three faces (two vertical faces and lower face of beam) wrap of carbon fiber in the shear zone. They found that the carbon fiber sheet improves the ultimate strength and ductility of tested beams.

Seven concrete beams reinforced externally with carbon FRP (fiber-reinforced polymer) laminates were examined after the concrete had cracked [5]. They showed that the application of carbon FRP laminates is very effective for flexural strengthening of reinforced concrete beams and that the beams reinforced with steel and carbon FRP have adequate deformation.

\section{Types of Failure in Concrete Structures}

Failure modes are determined in two main categories as flexural failure mode (Mode I) and shear failure mode (Mode II) with three subcategories for Mode II failure as follows:

- Mode II-1: diagonal tension failure, which, in the line of thrust, becomes so eccentric and gives rise to flexural failure in compressive zone. However, it is important to mention that this kind of failure is a result of tensile crack extension in compressive zone due to the flexural load;

- Mode II-2: shear compression failure where RC (reinforced concrete) beam fails due to the development of diagonal crack into the compressive zone reducing the area of resisting region excessively. The beam crushes once generated compressive stress exceeds the concrete compressive strength;

- Mode II-3: proper shear or compressive failure of struts, which is often observed in beams with very small shear span to depth ratio $a / d$ (the span to depth ratio is an important factor to classify the beam which is deep or shallow type as for control the deflection in one or two way structural members) (about $a / d<1.5$ ). In this case, due to the small a/d ratio, the line of thrust will be so steep and arch action will not only reserve flexural capacity in most cases but also efficiently sustains required shear force. Arch formation is clearly observed in those beams and, finally, beams will fail due to either sudden tensile crack formation parallel to the strut axes or concrete crushing in normal direction to the strut axes [6].

\section{Repairing Schemes and Test Setup}

All specimens are typical in dimensions of $100 \times$ $200 \times 1,000 \mathrm{~mm}$ (width $\times$ height $\times$ length) and the tensile reinforcement was $2 \varnothing 12 \mathrm{~mm}$ in tension zone and $2 \varnothing 10 \mathrm{~mm}$ in compression zone of the beam cross section, respectively. Specimen NS3 was the reference beam. After its failure, it was repaired by using continuous surface bonded U-wraps throughout the $1 / 3$ beam span from each support which is referred to as Specimen NS3C. The wraps were made of single-ply carbon fiber sheets with the fiber direction oriented perpendicular to the longitudinal axis of the beam. No end anchors were used for this Specimen NS3C. The CFRP (carbon fibre reinforced plastics) wraps were applied following the manufacturer recommendations. Prior to repairing, the concrete surface was prepared using water blasting then was allowed to dry. It was then coated with a layer of epoxy-based primer. After the primer became tack-free, a layer of putty and a thick paste epoxy were applied to level the surface and patch small holes. A first coat of saturate resin was then applied followed by the fiber sheets. A ribbed roller then rolled on the sheets to ensure the surface free of air bubbles. The sheet was then coated with a second layer of saturate resin and the excessive resin removed. The shear reinforcement of the beam is three stirrups 
of Ø5@50 mm on each side (Fig. 1a).

Specimen NS5 was repaired with $1 \mathrm{~mm}$ thick steel strip. The beam was bonded to the two vertical beam faces. The shear reinforcement of the beam is five stirrups of Ø5@50 mm on each side (Fig. 1b).

Specimen NS7 was repaired with one-ply carbon fiber strips in the form of a U-wrap. The strip width is $75 \mathrm{~mm}$ with center to center spacing of $125 \mathrm{~mm}$. The shear reinforcement of the beam is seven stirrups of
Ø5@50 mm on each side (Fig. 1c).

Specimen HS5 was repaired with CFRP strips attached on the two sides and bottom surface of the beam. The shear reinforcement of the beam is $5 \varnothing 5$ mm on each side (Fig. 1d).

Specimen HS7 was repaired in a manner similar to that of Specimen NS5. The shear reinforcement of the beam was seven stirrups of Ø5@50 mm on each side of the beam (Fig. 1e).

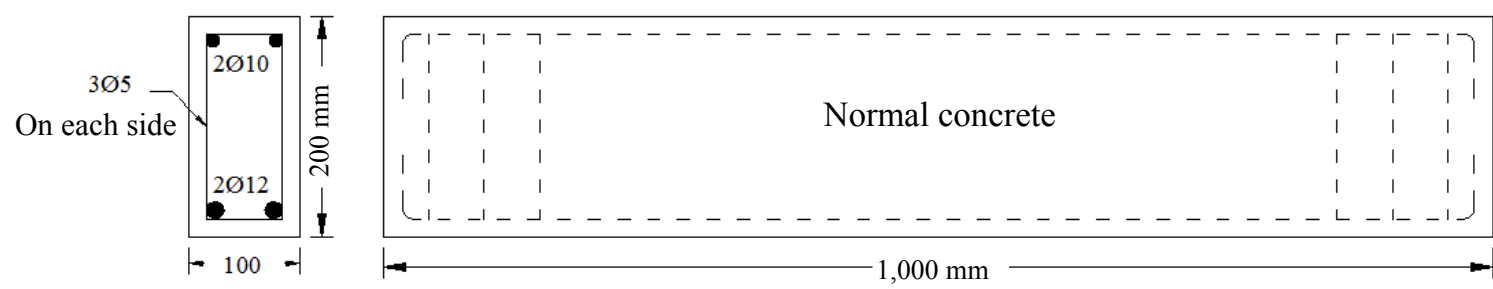

(a)

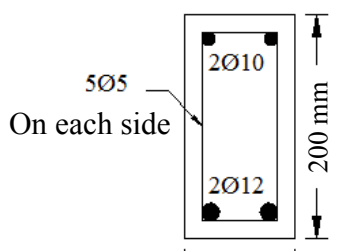

100 -
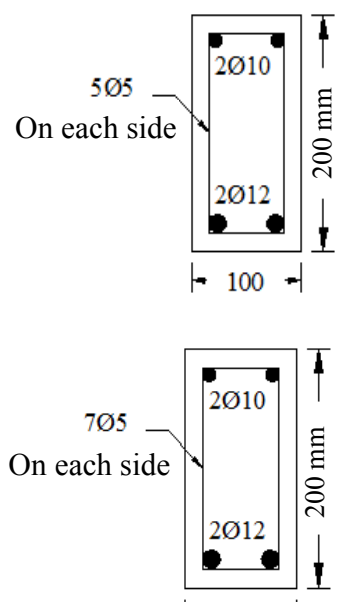

$100-$

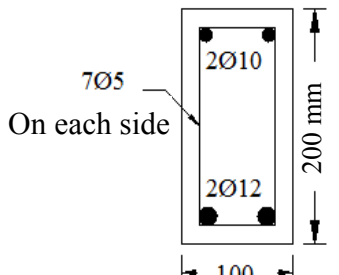

$-100-$

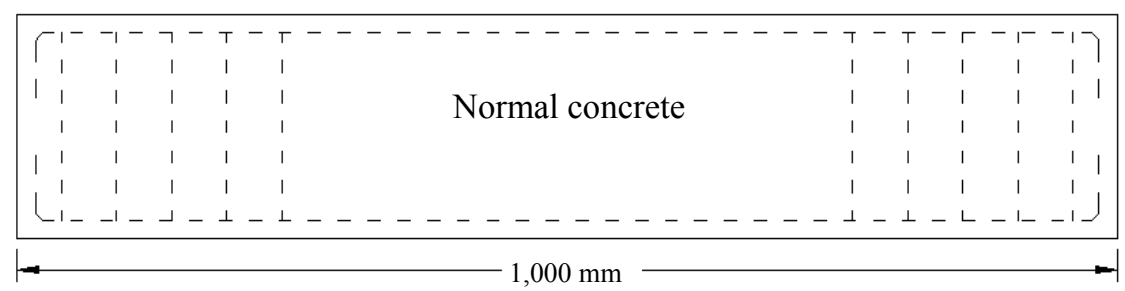

(b)

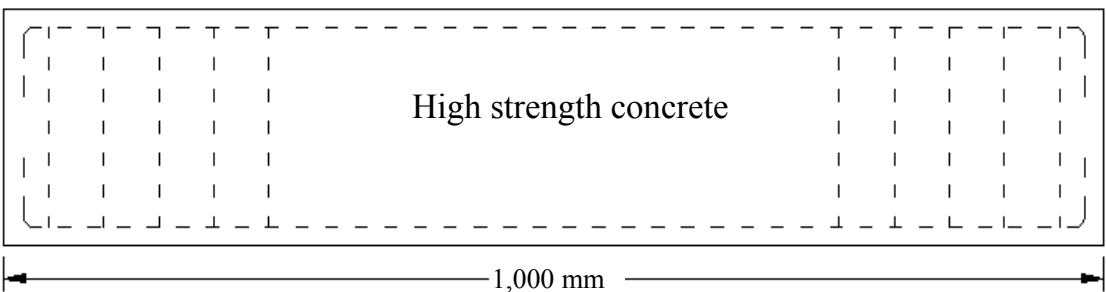

(c)

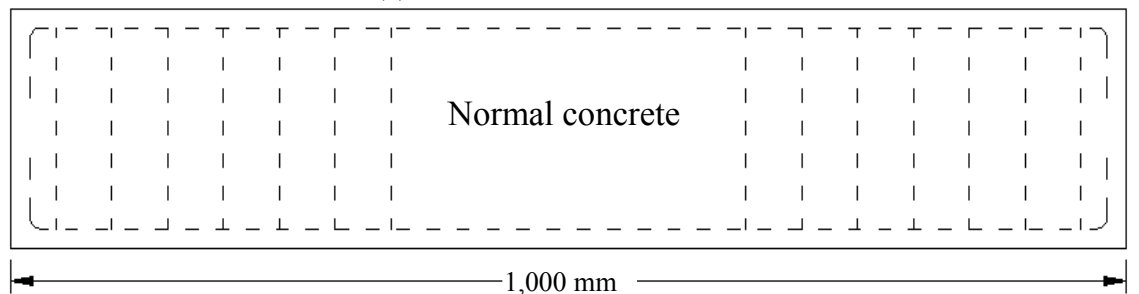

(d)

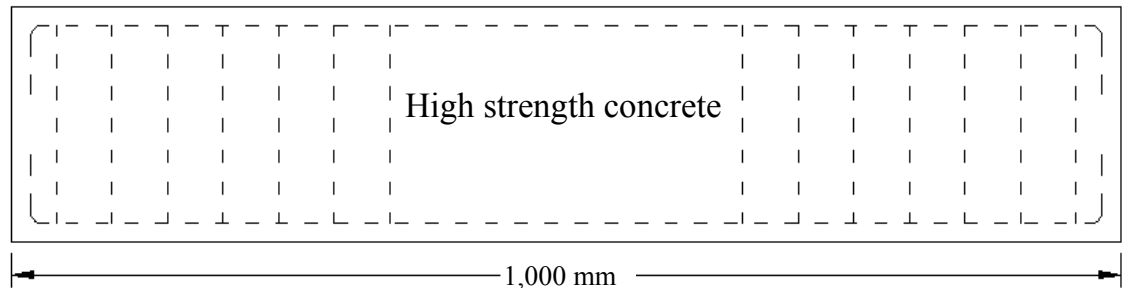

(e)

Fig. 1 Characteristics of beam: (a) NS3; (b) NS5; (c) HS5; (d) NS7; (e) HS7. 
Strengthening schemes and experiment setup of the tested beams are shown in Fig. 2. All specimens were tested as simple beams under four-point bending, two-point loading with $300 \mathrm{~mm}$ distance between two point loads. A loading machine of $3,000 \mathrm{kN}$ capacity was used in order to apply a concentrated load on a steel distribution beam used to generate the two concentrated loads. Load is applied in increments of 2 $\mathrm{kN}$ till failure and deflection is recorded during the test.

Dial gauge is used to measure the deflection of beams at every load stage. The dial gauge is placed directly under the centerline of the beam to measure mid-span deflection. The dial gauge has an accuracy of $0.01 \mathrm{~mm}$ as shown in Fig. 2.

\section{Experimental Program}

\subsection{Test Specimens and General Procedure}

Two types of concrete mix were cast using ordinary Portland cement, river sand $5 \mathrm{~mm}$ maximum size and graveled with maximum size of $12 \mathrm{~mm}$, with large amount of crushed aggregate and a minimum amount of flat and elongated particles. The type of cement used in this study is ordinary Portland cement (Type I). Each series contained different mix proportions, i.e., one normal strength concrete with the formulation of $w / c$ (water to cement) $=0.44 \%$, cement $415 \mathrm{~kg} / \mathrm{m}^{3}$, sand $535 \mathrm{~kg} / \mathrm{m}^{3}$ and gravel $1,250 \mathrm{~kg} / \mathrm{m}^{3}$ and another high strength concrete with the formulation of $w / c$ of $0.28 \%$, cement $541 \mathrm{~kg} / \mathrm{m}^{3}$, sand $774 \mathrm{~kg} / \mathrm{m}^{3}$ and gravel $984 \mathrm{~kg} / \mathrm{m}^{3}$. The main differentiation laid on the

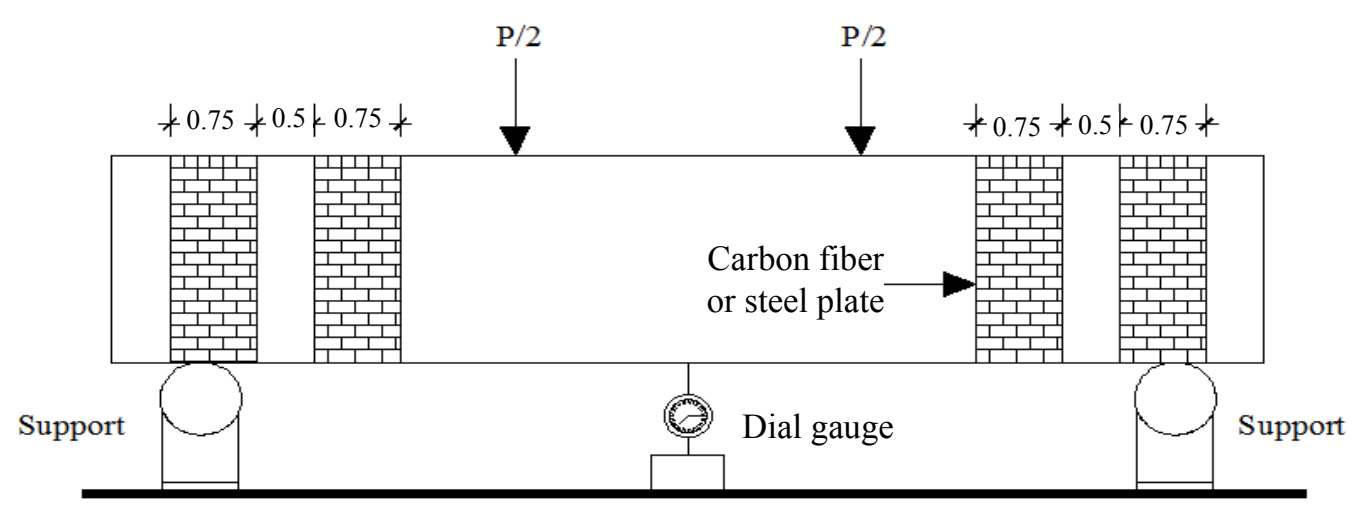

addition of super plasticizer $7 \mathrm{~L} / \mathrm{m}^{3}$ into the high strength concrete mixture.

Concrete cylinders (Ø150 mm $\times 300 \mathrm{~mm}$ ) were cast in two layers. Each layer is compacted using table vibrator for $3 \mathrm{~s}$ for the first layer and $5 \mathrm{~s}$ for the second. After casting, the specimens are covered with wet burlap under polyvinyl sheet. On the next day, the cylindrical specimens are de-molded and cured in water up to the age of 28 days. The compressive test was done according to ASTM (American Society for Testing and Materials) C39 [7] and B.S (British Standards) 1881 [8] by using a computerized machine in the Materials Laboratory, College of Engineering, Al-Mustansiriya University, Iraq, with a loading capacity of $1,000 \mathrm{kN}$. The cylindrical and cubical compressive strength is shown in Table 1.

The reinforcing steel is deformed. The average yield strength is $435 \mathrm{MPa}$. The average ultimate strength is $601 \mathrm{MPa}$ and the reinforcing steel bar is 10 $\mathrm{mm}$ and $12 \mathrm{~mm}$ in diameter for compression and tension, respectively.

The thickness of glued steel strips is $1 \mathrm{~mm}$. Steel strip is made with $75 \mathrm{~mm}$ in width and $200 \mathrm{~mm}$ in length and attached to the beam surface by special epoxy. The yield and ultimate strengths are shown in Table 2.

The mechanical and physical properties of the bonding material are shown in Table 3.

The mechanical and physical properties of carbon fiber are presented in Table 4.

Fig. 2 Loading set up and repairing scheme (m). 
Table 1 Compressive strength of tested beams.

\begin{tabular}{lll}
\hline Specimens & $\begin{array}{l}\text { Cube strength } f_{c u} \\
(\mathrm{MPa})\end{array}$ & $\begin{array}{l}\text { Cylinder strength } f_{c}^{\prime} \\
(\mathrm{MPa})\end{array}$ \\
\hline NS3 & 36 & 27.13 \\
NS5 & 33.15 & 24.93 \\
HS5 & 49.3 & 38.65 \\
NS7 & 31.8 & 23.1 \\
HS7 & 54 & 42.82 \\
\hline
\end{tabular}

Table 2 Yield strength and ultimate strength of steel strip plates.

\begin{tabular}{llll}
\hline No. & $\begin{array}{l}\text { Thickness } \\
(\mathrm{mm})\end{array}$ & $\begin{array}{l}\text { Yield strength } \\
(\mathrm{MPa})\end{array}$ & $\begin{array}{l}\text { Ultimate strength } \\
(\mathrm{MPa})\end{array}$ \\
\hline 1 & 1 & 290 & 415 \\
2 & 1 & 310 & 406 \\
3 & 1 & 313.6 & 418 \\
4 & 1 & 305.3 & 412.4 \\
\hline
\end{tabular}

Table 3 Mechanical and physical properties of bonding material.

\begin{tabular}{ll}
\hline Properties & Values \\
\hline Tensile strength & $30 \mathrm{~N} / \mathrm{mm}^{2}\left(7\right.$ days at $\left.+23^{\circ} \mathrm{C}\right)$ \\
\hline Bond strength & $\begin{array}{l}\text { Concrete fracture }\left(>4 \mathrm{~N} / \mathrm{mm}^{2}\right) \text { on } \\
\text { sandblasted substrate: }>1 \text { day }\end{array}$ \\
\hline \begin{tabular}{l} 
E-Modulus \\
$\begin{array}{l}\text { Flexural: } 3,800 \mathrm{~N} / \mathrm{mm}^{2}\left(7 \text { days at }+23^{\circ} \mathrm{C}\right) \\
\text { Tensile: } 4,500 \mathrm{~N} / \mathrm{mm}^{2}\left(7 \text { days at }+23^{\circ} \mathrm{C}\right)\end{array}$ \\
\hline break
\end{tabular} & $0.9 \%\left(7\right.$ days at $\left.+23{ }^{\circ} \mathrm{C}\right)$ \\
\hline
\end{tabular}

Table 4 Mechanical and physical properties of carbon fiber.

\begin{tabular}{ll}
\hline Properties & Values \\
\hline Tensile strength & $4,300 \mathrm{~N} / \mathrm{mm}^{2}$ \\
Tensile E-modulus & $234,000 \mathrm{~N} / \mathrm{mm}^{2}$ \\
Elongation at break & $1.8 \%$ \\
\hline
\end{tabular}

\subsection{CFRP Installation}

Beams are severely damaged due to excessive loading in the tests. Repairing work is represented by bonding carbon fiber (or steel plate) by glue, externally at the shear zone. The work is outlined as follows:

(1) The first step in repairing is to restore the original shape of the specimen. This is done by applying a reverse load from testing machine to the beam until it becomes straight again or nearly so;

(2) The position of steel plate is drawn and limited by cement mortar on the surface of the beam, after which, the sika dur (glue) is poured in that position and left for $45 \mathrm{~min}$ to start hardening and then, the steel plate and carbon fiber strip are glued at its position;

(3) Specimen preparations are repeated before testing, with painting the surface by white emulsion.

\section{Results and Discussion}

\subsection{Effect of Repairing Techniques}

\subsubsection{Strength and Efficiency}

The strength of the tested beams is expressed as the experimented ultimate load the beam can withstand. The efficiency of repairing is defined as the ratio of the repaired beam strength to its original strength (as a percentage).

One of the two beams in each group is provided with external carbon fiber and steel plate in flexural and shear zone.

The beam NS3C (which is repaired with carbon fiber) records an increase of $14.5 \%$ in strength above its original strength, which means that the beam exhibits $114.5 \%$ repair efficiency. The two beams repair materials restored the beams to their full capacity compared with the control beam in terms of short-term structural efficiency.

The ultimate failure of the repaired beam occurred by crushing of the concrete at the support as well as the wide shear cracks and separation of carbon fiber sheet from beam side, while the failure of reference model by shear only. After repairing by carbon fiber method, the increased load-carrying capacity comes from the external carbon fiber sheet.

For Group 4, at final step of load application, the beam with carbon fiber plating reached higher load level. The stiffness of the carbon plated beam exhibits cracking load at about $6.5 \mathrm{kN}$ and they failed by same manner (shear) separation between carbon fiber and beam occurring at the end of loading application. A piece of concrete is removed from the beam with carbon fiber strip. Brittleness of failure can be seen in reference Specimen NS3 more than the repaired Beam NS3C which may be caused by high bonding 
characteristics between carbon fiber and concrete in Beam NS3C. This is not seen in Beam NS3.

The second group consists of two specimens, one is repaired using steel plates and the other does not contain any type of repair. The used concrete is the normal concrete used on each side of the beam as shear reinforcement.

The general behavior of this group does not differ much from the previous group. The ultimate failure of the repaired beam occurred at an average load of 36 $\mathrm{kN}$, which corresponds to a $16.1 \%$ increment in the ultimate load carrying capacity of the reference beam. This means that the repair efficiency is $116.1 \%$.

The ultimate failure of the repaired beam occurred by crushing of the compression toe under point load as well as the wide shear cracks and separation of steel plate from beam side, whereas, the failure of reference model by shear only. After repairing by plating method, the tensile strength of the beam consists of two components, the external steel plate and the internal yielded steel. The additional capacity comes from the external steel plate.

From Tables 1-4, it can be seen that the ratio of the ultimate load capacity of the Beam NS7C to that of control beam (Group 3) is $2.3 \%$. These results indicate that the repair techniques performed using carbon fiber was higher than that of the un-plated beam by about $20.6 \%$, so the repairing stiffness was $120.6 \%$, resulting in higher load carrying capacity at lower deformation levels.

The beam repaired by using the steel strips in Group 5 differs from beams in other groups in ultimate strength. It was observed that the repaired Beam HS7S did not acquire the strength of the original beam (reference beam). The amount of decrement in resistance of repaired beam reached $8.2 \%$ in comparison with reference Specimen HS7 (Tables 1-4). This is due to the high resistance of the reference specimen, so we need additional amount of steel strip for the purpose of regaining the original resistance of the model. This is mentioned in the recommendations of this paper.

In comparison with Abdelhak's results [3], there is an improvement in shear capacity reaching $49.8 \%$ when CFRP is used in shear zone. The improvement in shear capacity reached $20 \%$ over original strength. The difference between them is that the CFRP sheet in Ref. [3] includes the whole shear zone, but in this work, not all the shear zone is covered by the CFRP sheet.

\subsubsection{Deflection and Ductility}

Deflection results at cracking load, yielding load and ultimate load of original beams are compared with those of the repaired beams, as shown in Table 5 . Deflection of all beams is measured at mid-span of the beams and plotted versus the load, as shown in Figs. 1-4. Load deflection curves of the beams through loading stages up to failure consist of several main

Table 5 Load characteristics and failure mode of tested beams.

\begin{tabular}{lllll}
\hline Specimen & $\begin{array}{l}\text { Cracking load } P c r^{*} \\
(\mathrm{kN})\end{array}$ & $\begin{array}{l}\text { Ultimate load } P u^{* *} \\
(\mathrm{kN})\end{array}$ & $\begin{array}{l}\text { Repair efficiency } \\
P u / P c r\end{array}$ & Mode of failure \\
\hline NS3 & 7 & 27.5 & 114.5 & $\begin{array}{l}\text { Shear } \\
\text { NS3C }\end{array}$ \\
\hline NS5 & 6.5 & 31.5 & 116.1 & Shear and separation of carbon fiber \\
NS5S & 7 & 31 & 102.3 & Shear and separation of steel plate \\
\hline NS7 & 7 & 36 & 120.6 & Shear \\
NS7C & 6.5 & 44 & Shear and separation of carbon fiber \\
\hline HS5 & 7 & 45 & Shear \\
HS5C & 7.5 & 51 & Shear and separation of carbon fiber \\
\hline HS7 & 7.5 & 61.5 & 91.8 & Shear \\
HS7S & 7.5 & 61 & Shear and separation of steel plate
\end{tabular}

*Pcr stands for the load which the crack appeared the stress at this instant reached the modulus of rupture of beam;

**Pu stands for the failure load which the deflection of beam increases rapidly at advanced stages of load application. 
stages. The first stage is from starting load application up to the formation of the first crack and it is approximately linear. In the second stage, the beam becomes less rigid because of the reduction in its stiffness due to the development of cracks. It is also approximated as linear between load and deflection but has smaller slope extending from cracking load point to yield load point. The final part extends from yield load point up to the failure.

All the deflection values of repaired Beam NS3C are less than that of corresponding original Beam NS3 (Fig. 3). This means that the improvement in repaired beam stiffness at all loading states is due to the glued carbon fiber at the flexural and shear zone of the beam. Ductility index which is defined as the ratio of deflection at the ultimate load to the deflection at yielding also has an improvement in repaired beam in comparison with the original beam by about $2.86 \%$.

The second group beams were loaded in the same pattern as the previous group beams. The load deflection curve of this group passes through the same stages as in Group 1 (Fig. 4). The deflection from initial loading stages up to failure load of the repaired Beam NS5S is less than that of the reference Beam NS5. The use of external steel plates increases the moment of inertia $(I)$ of the section and the stiffness of the repaired beam, thereby, the deflection will decrease.

Also, ductility index was increased about $64.37 \%$ over reference specimen.

The load-deflection curves for beams repaired with carbon fiber, as well as for the control beam, are shown in Fig. 5. The actual maximum deflections at mid-span were measured and plotted against actual loads. The beam specimens repaired by using carbon fiber (NS7C) showed almost similar load-deflection curves to that of the control beam. As stiffness and ductility are directly related to deflection, it appears that the repaired beams are equally capable of restoring their full stiffness and exhibiting ductility of $439 \%$ with respect to control beam.
Fig. 5 shows the deflection of the beams at different loading stages. The deflections of all the repaired beams at first crack are similar to that of the control beam.

Beam repaired using the carbon fiber strips (Group 4) showed smaller deflections compared to the control beam. This may be attributed to that the stiffness of the HS5C carbon fiber plated beam is higher than that of the reference beam without carbon fiber (Fig. 6).

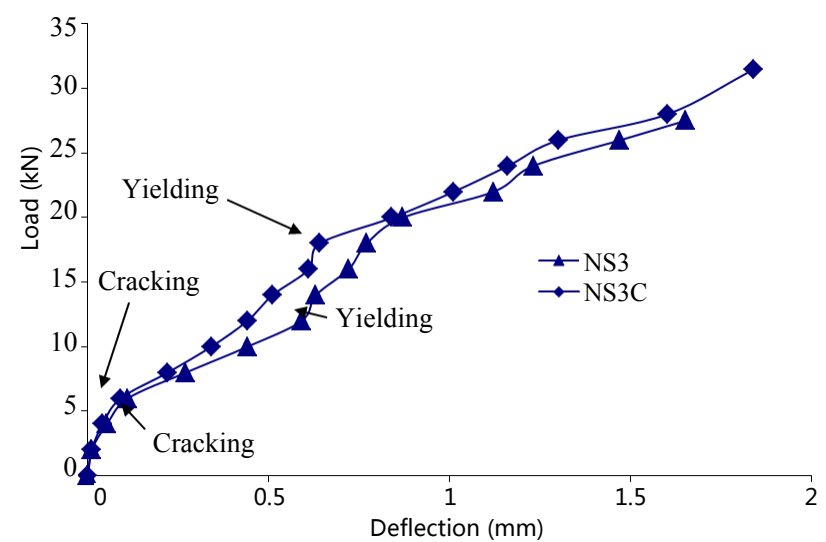

Fig. 3 Load-deflection curve of Group 1.

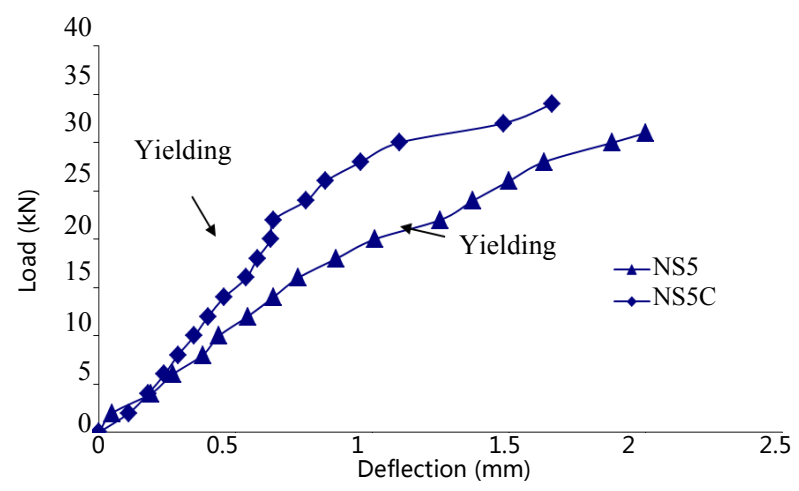

Fig. 4 Load-deflection curve of Group 2.

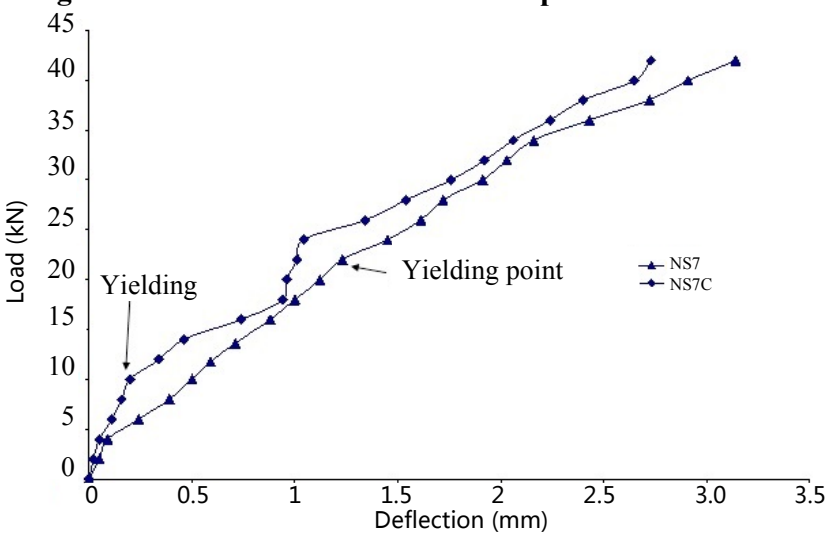

Fig. 5 Load-deflection curve of Group 3. 


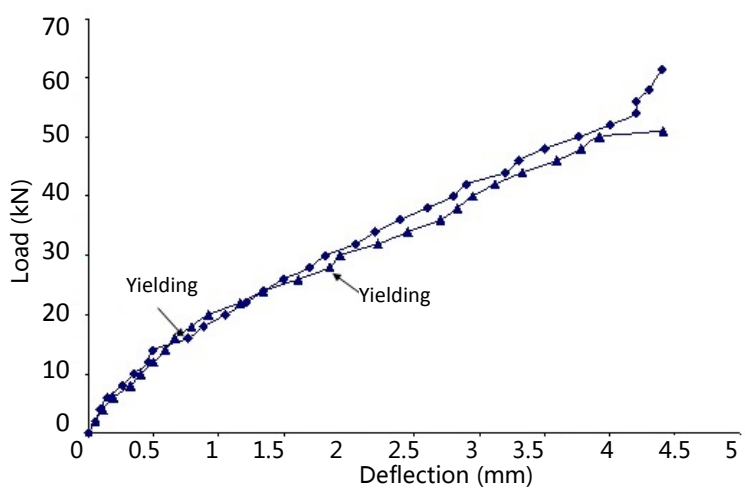

Fig. 6 Load-deflection curve of Group 4.

Table 6 shows the deflection and deflection ductility values. In the case of carbon fiber plated beams, the deflection ductility values showed a clear improvement by about $146.6 \%$ in comparison with that of reference specimen.

The general behavior of Group 5 is not much different from other groups. The three stages were observed clearly in the load-deflection curve which represents the stages of the failure of tested beams through the stages of loading until failure. This is mentioned previously in the other groups that stiffness of the HS7S steel plated beam is higher than that of the reference beam without steel plate (Fig. 7).

Despite the lack of development of ultimate strength, there is a clear development in the values of ductility index about $126.6 \%$ with respect to reference specimen.

\subsubsection{Crack Pattern and Failure Mode}

The initial cracking of all the tested beams was first observed in the tension face of flexural zone under the point load. In original and repaired beams, the first crack opened parallel to the direction of load application and, at the advanced stages of load application, a relatively wide shear cracks can start at the support towards point load.

In general, width of crack in repaired Beam NS3C is wider than that of reference Beam NS3, and the maximum crack width at failure of Beam NS3C is more than that in Beam NS3. This is because the longitudinal carbon fiber strip works as a bridge connecting the sides of beams beside the crack. This causes the failure to occur with crack width more
Table 6 Deflection and ductility of tested beams.

\begin{tabular}{lllll}
\hline Specimens & $\begin{array}{l}\text { Deflection } \\
\text { at yield }\end{array}$ & $\begin{array}{l}\text { Ultimate } \\
\text { deflection }\end{array}$ & Ductility & $\begin{array}{l}\text { Improvement } \\
\text { in ductility (\%) }\end{array}$ \\
\hline NS3 & 0.59 & 1.65 & 2.79 & 2.86 \\
NS3C & 0.64 & 1.84 & 2.87 & \\
NS5 & 1.25 & 2.0 & 1.6 & 2.63 \\
NS5S & 0.63 & 1.66 & 2.63 & \\
NS7 & 1.23 & 3.14 & 2.55 & 43.13 \\
NS7C & 0.20 & 2.73 & 3.65 & \\
HS5 & 1.85 & 4.41 & 2.38 & 136.86 \\
HS5C & 0.76 & 4.4 & 5.87 & \\
HS7 & 1.93 & 5.8 & 3 & 126.6 \\
HS7S & 0.44 & 3 & 6.8 & \\
\hline
\end{tabular}

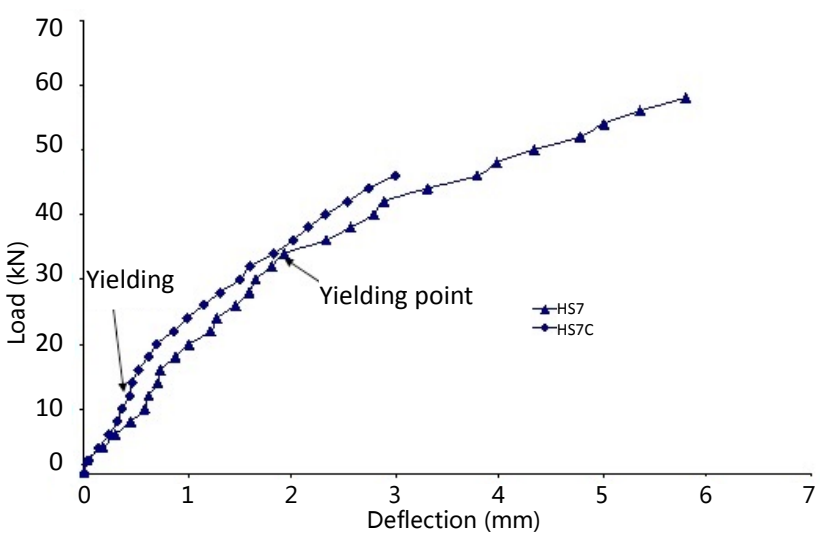

Fig. 7 Load-deflection curve of Group 5.

often than that in the samples without carbon fiber. There is no clear improvement in first cracking appearance in all tested beams (original and repaired).

The location of first cracking load in Groups 2-5 is the same as that in previous group. It starts at the tension face of beams towards the point load. At the advanced stages of load application, the shear mode failure takes place either by diagonal cracks initiating at the plate ends and extending with orientation degree less than $45^{\circ}$. In general, the crack width at failure in repaired Beams NS5S, NS7C, HS5C and HS7S is wider than the crack width of reference beams. The steel plate and carbon sheet were separated from beam at advanced loading stages (Figs. 8-15).

\subsection{Effect of High Strength Concrete}

\subsubsection{Strength}

By observing the results of the tested beams listed in Table 5, it is noticed that the value of the ultimate load increases as the value of the concrete strength 


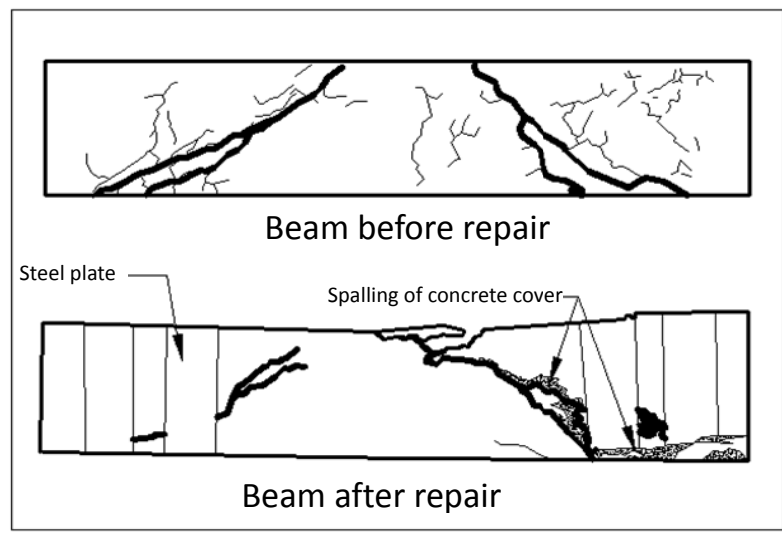

Fig. 8 Crack pattern of Group 1.

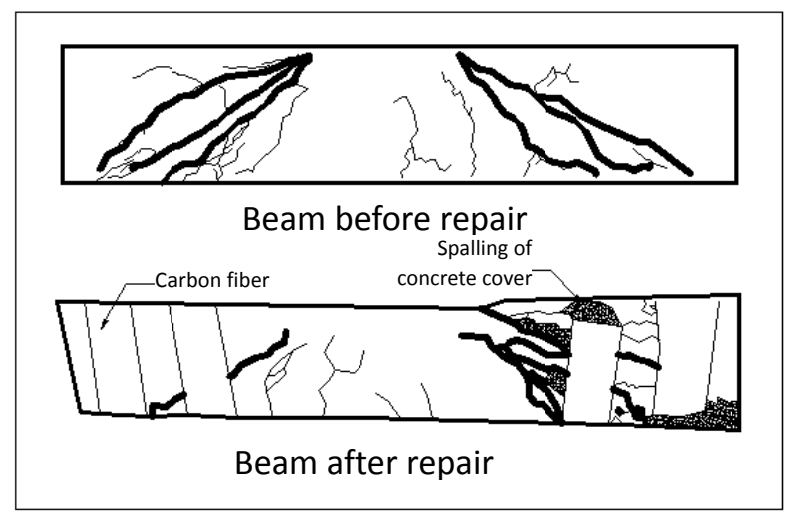

Fig. 9 Crack pattern of Group 2.

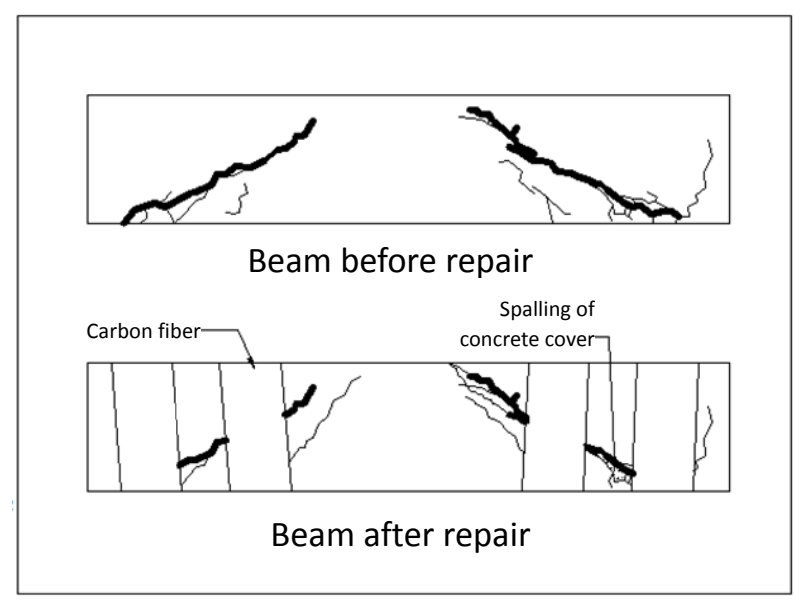

Fig. 10 Crack pattern of Group 3.

increases. Increasing the compressive strength of concrete increases yielding load, and this is because the use of high-strength concrete causes increased internal moment arm resulting from multiplying the resulting force of the concrete area above the neutral axis by the distance between the center of this area to the center of rebar in the tension face of section.

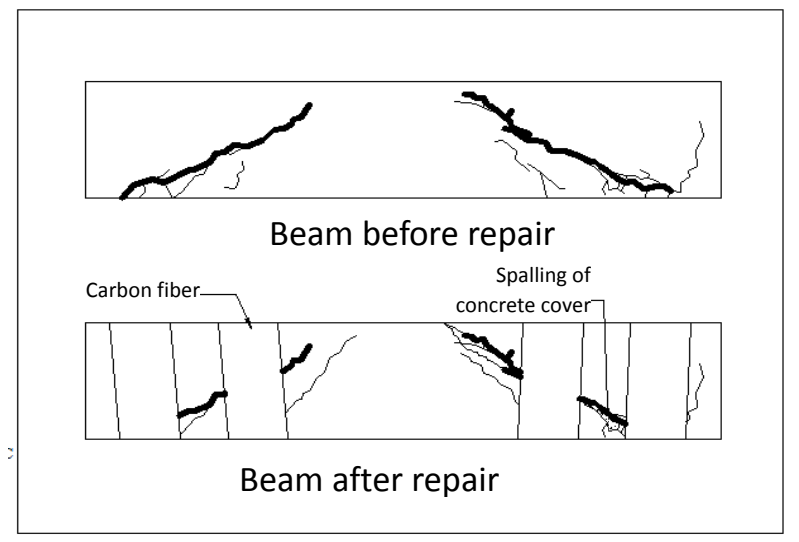

Fig. 11 Crack pattern of Group 4.

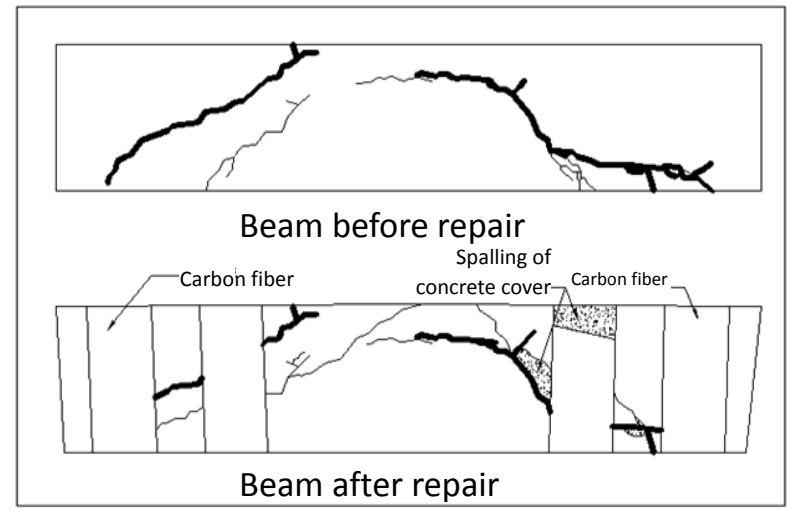

Fig. 12 Crack pattern of Group 5.

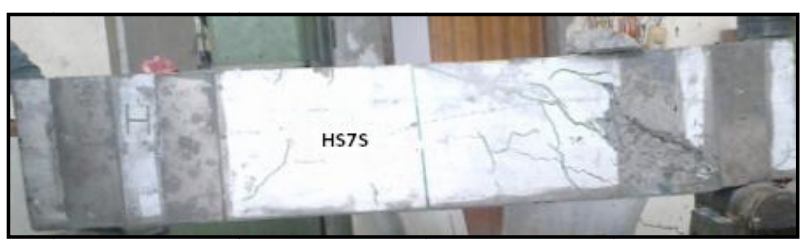

Fig. 13 Typical crack pattern of beams repaired with steel plate.

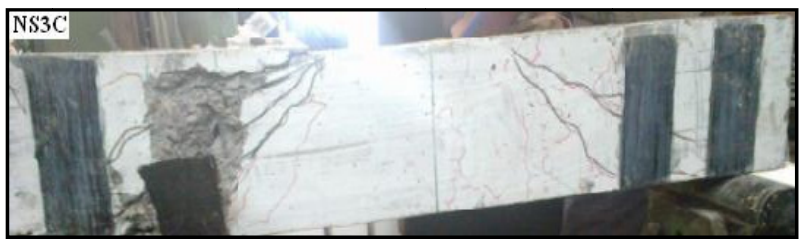

Fig. 14 Typical crack pattern of beams repaired with carbon fiber.

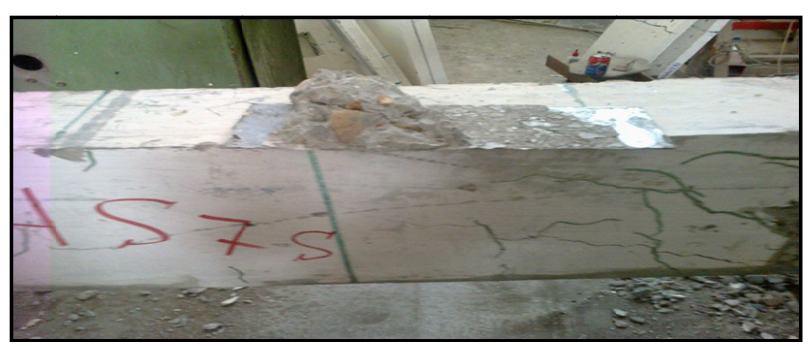

Fig. 15 Separation of concrete cover. 


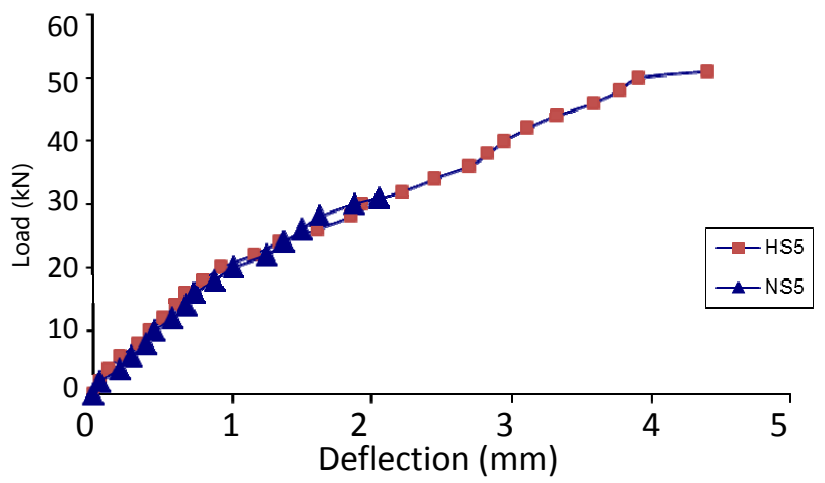

Fig. 16 Load deflection curve of HS5 and NS5.

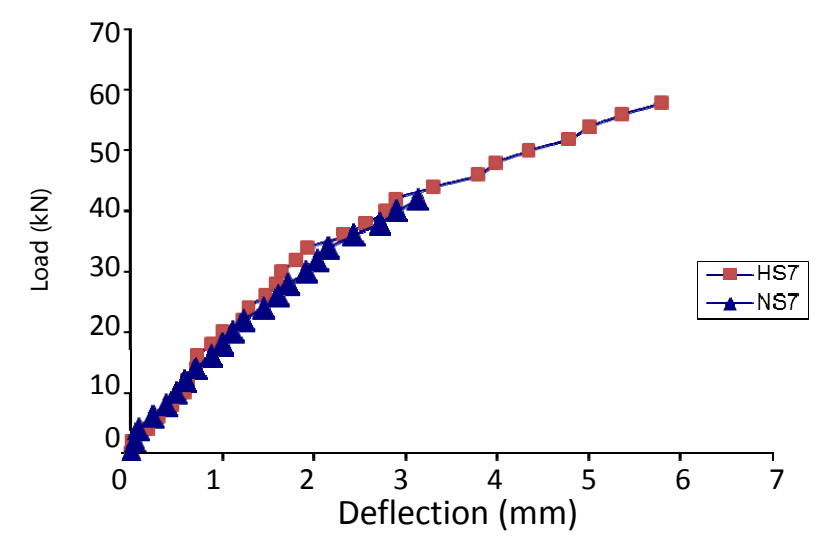

Fig. 17 Load deflection curve of HS7 and NS7.

\subsubsection{Deflection and Ductility}

The load-deflection curves in Figs. 3-7 show, as expected, a lower stiffness and greater ductility of the high strength concrete beams compared with that of the normal concrete beams. This may be attributed to the difference in stiffness between an integrated (normal) beam and a bonded (high) beam.

The ductility of high-strength concrete beam members with various concrete compressive strengths iscompared in Figs. 16 and 17 based on the results of this research. When the tensile reinforcement is kept constant, the load-deflection behavior below the yielding of reinforcement sharply changes with the change in compressive strength, but it varies greatly after the yield. The increase in deflection varies proportionally with the load increase. Thus, the general trend of increasing ductility with the increase in concrete strength is observed. The bending strength increased by about $49 \%$ as the compressive strength increased from 24.93 $\mathrm{MPa}$ to $38.65 \mathrm{MPa}$ and about
$18 \%$ as the compressive strength increased from 23.1 $\mathrm{MPa}$ to $42.82 \mathrm{MPa}$. Thus, it was verified that high-strength concrete is effective in improving the ductility of the member, given the same tensile reinforcement ratio.

\subsection{Effect of Shear Reinforcement on Ultimate Strength}

Through the study of behavior of reinforced beams, taking the amount of reinforcement used in the shear zone into consideration shows that there is a significant increase in the failure load of the model reaching $12.72 \%$ when increasing the number of stirrups in each side of beam from three in Beam NS3 to five in Beam NS5, and reaching $60 \%$ when increasing to seven stirrups in each side of Beam NS7. In high strength concrete models, the conclusion is that there is an increase in ultimate capacity about $19.6 \%$ when increasing the number of stirrups in each side of beam from five to seven in HS5 and HS7, respectively. The expected increment in shear strength resulting from the delay in cracks growth is due to the increasing number of stirrups.

\section{Conclusions}

There are six points can be drawn as follows:

(1) The use of both types of repair using either carbon fiber or steel plates generates an increase in ultimate load capacity as well as the development of ductility in each repaired beam;

(2) The value of deflections occurring in the model through the process of applying loads in repaired models is less than those models without repair;

(3) The maximum crack width at failure of tested beams is greater than that in control beams because the longitudinal carbon fiber strip works as a bridge connecting the sides of beams beside the crack;

(4) When using high-strength concrete, an increase in carrying load capacity of the model is observed;

(5) Through the study of load-deflection curve, it appeared that the models with the highest compressive 
strength have lower stiffness and greater ductility for the high strength concrete beams compared with the normal concrete beams;

(6) Increasing the number of stirrups in the shear zone generates an increase in failure load.

\section{References}

[1] G. Andrews, A.K. Sharma, Repaired reinforced concrete beams failing in shear, Concrete International 12 (3) (1990) 53-57.

[2] ACI (American Concrete Institute) Committee, Causes, Evaluation and Repair of Cracks in Concrete Structures, American Concrete Institute, 1998.

[3] B. Abdelhak, C. Omar, Behavior of reinforced concrete t-beams strengthened in shear with carbon fiber-reinforced polymer-An experimental study, ACI Structural Journal 103 (3) (2006) 339-347.
[4] P. Carlo, M. Claudio, Strength and ductility of concrete beams reinforced with carbon FRP and steel, ACI Structural Journal 103 (5) (2006) 720-728.

[5] D. Dat, S. Monica, Strength and Ductility of Concrete Beams Reinforced with Carbon FRP and Steel, National Institute of Standards and Technology, Gaithersburg, 2011.

[6] R.S. Mohammad, H. Kobayashi, S. Unjoh, Experimental and Analytical Study on RC Deep Beams, Public Works Research Institute, Earthquake Engineering Team, Earthquake Disaster Prevention Research Group, Tsukuba, Japan, 2005.

[7] ASTM C39-86, Test Method for Compressive Strength of Cylindrical Concrete Specimens, ASTM International, 2003.

[8] BS 1881: Part 116: 1983, Method for Determination of Compressive Strength of Concrete Cubes, Park Street, London, 1983 